\title{
Joining of TiAl alloys using Ni/Al multilayers
}

\author{
S. Simões ${ }^{*}$, F. Viana*, V. Ventzke ${ }^{* *}$, M. Koçak ${ }^{* *}$, A. S. Ramos ${ }^{* * *}$, M. T. Vieira ${ }^{* * *}$ and M. F. Vieira ${ }^{*}$ \\ * CEMUC, Dep. de Engenharia Metalúrgica e Materiais, Faculdade de Engenharia, Universidade do \\ Porto, Rua Dr. Roberto Frias, 4200-465 Porto, Portugal \\ ** GKSS Research Center, Institute of Materials Research, Max-Planck Str., Geesthacht, Germany \\ *** CEMUC, Departamento Engenharia Mecânica, Faculdade de Ciências e Tecnologia da \\ Universidade de Coimbra, R. Luís Reis Santos, 3030-788 Coimbra, Portugal \\ mvieira@fe.up.pt
}

The development of joining processes for TiAl alloys is fundamental to integrate them into functional structures and to widen their application field. Diffusion bonding has become the most reported technique for joining TiAl alloys but have the disadvantage of requiring high temperature stages. Diffusion bonding of TiAl at the $950-1200^{\circ} \mathrm{C}$ temperature range has been reported to produce defect-free bonds. Çam et al. [1], successfully joined TiAl at $950{ }^{\circ} \mathrm{C} / 30 \mathrm{MPa} / 3 \mathrm{~h}$ and $1000{ }^{\circ} \mathrm{C} / 30 \mathrm{MPa} / 1 \mathrm{~h}$, however, the bond interfaces were clearly visible.

In this work, we joined $\mathrm{TiAl}$ to $\mathrm{TiAl}$ with $\mathrm{Ni} / \mathrm{Al}$ multilayer thin films to reduce the temperature and time of the diffusion bonding cycle. Making use of the improved diffusivity of these nanometric layers and of the heat evolved from the exothermic reaction that occurs in the multilayer to enhance diffusion and achieve bonding at lower temperatures/time or pressure [2]. The multilayer was deposited into TiAl samples by d.c. magnetron sputtering with periods of 5, 14 and $30 \mathrm{~nm}$. The microstructure of the Ni/Al multilayer was studied by transmission electron microscopy (TEM) and scanning transmission electron microscopy (STEM), Cross-section images of Ni/Al multilayers with $14 \mathrm{~nm}$ of period reveal the layered structure (TEM image in Fig 1A) while the ring-like diffraction pattern confirms the fine grain size observed in as-deposited sample. The period of the multilayer was confirmed by STEM image (Figlb).

Joining experiments were performed in a vertical furnace with a vacuum level better than $10^{-4}$ mbar. Diffusion bonding joints were produced at a temperature of $900^{\circ} \mathrm{C}$, pressure of $5 \mathrm{MPa}$ and bonding times of 30 and $60 \mathrm{~min}$. The microstructure of the cross-sections of the bond interfaces were analysed by scanning electron microscopy (SEM) and energy dispersive X-ray spectroscopy (EDS). The observation of the interface for 30 and $14 \mathrm{~nm}$ period multilayer with $60 \mathrm{~min}$. of bonding time, presented in Fig. 2 and 3, revealed regions with an apparent soundness, while for $5 \mathrm{~nm}$ period porosity and cracks inside the interlayer thin film can be observed,. The interface could be divided into two distinct zones: one with columnar grains adjacent to the TiAl alloy (zone 1) and a central one with equiaxed grains (zone 2). The EDS chemical composition indicated that zone 1 is a reaction layer between the $\mathrm{TiAl}$ substrate and the multilayer, while zone 2 corresponds to the $\mathrm{NiAl}$ multilayer zone with small amounts of Ti (2 - 4 at.\%). For sample bonded for $30 \mathrm{~min}$. (Fig 3A) we observed a joint without pores or cracks; however we can clearly identify the bond line. The central region of the interface presents a mixture of small and large grains the later being observed close to bond line. The joining mechanism appears to depend on the diffusion of $\mathrm{Ni}$ and $\mathrm{Ti}$ across the interface, as confirmed by the net flux of Ni towards the TiAl alloy and of Ti towards the multilayer, evidenced by the composition profile in Fig. 3.

[1] G. Çam, M. Koçak, Journal of Materials Science 34 (1999) 3345

[2] L. Duarte, A. S. Ramos, M. F. Vieira, F. Viana, M. T. Vieira and M. Koçak, Intermetallics 14 (2006) 1151 
This work was supported by "Fundação para a Ciência e a Tecnologia" through the project PTDC/CTM/69645/2006 and the Grant SFRH/BD/30371/2006 financed by POS_C.
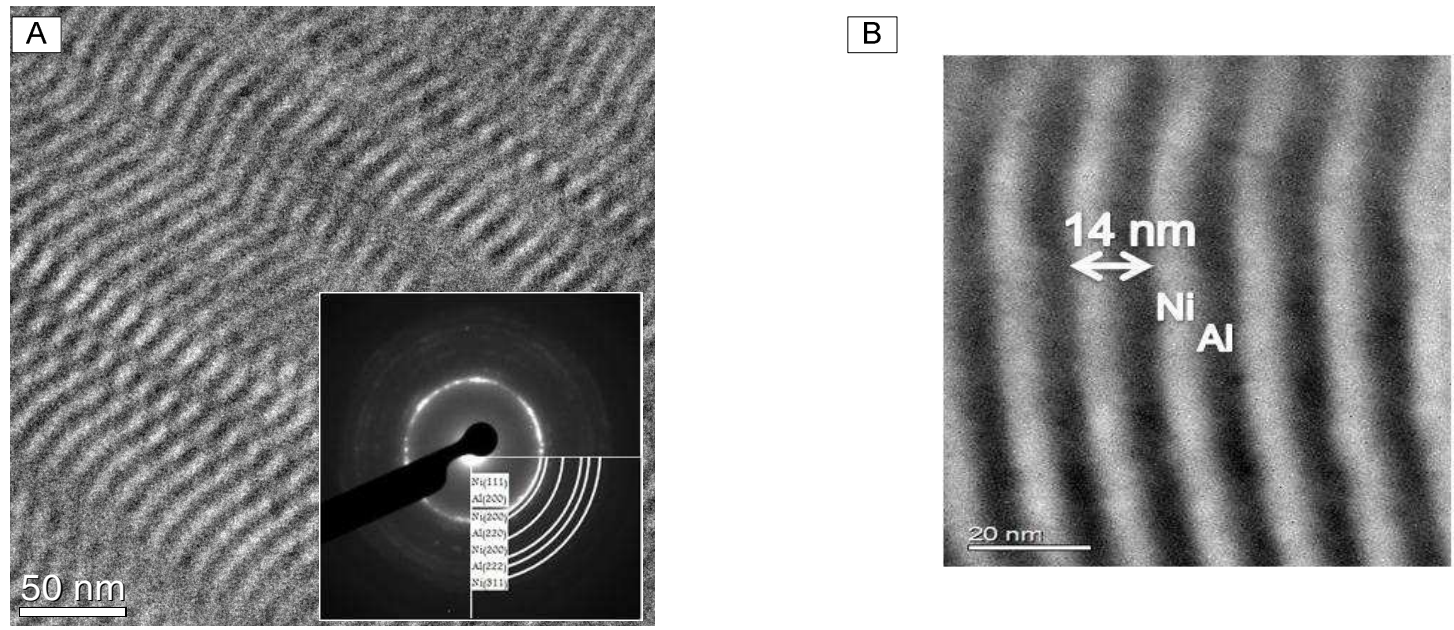

Fig. 1 - Ni/Al multilayer with $14 \mathrm{~nm}$ of period: A. TEM image and ring-like diffraction pattern; B. STEM image where the bright layers is $\mathrm{Ni}$ and the dark layers is $\mathrm{Al}$.
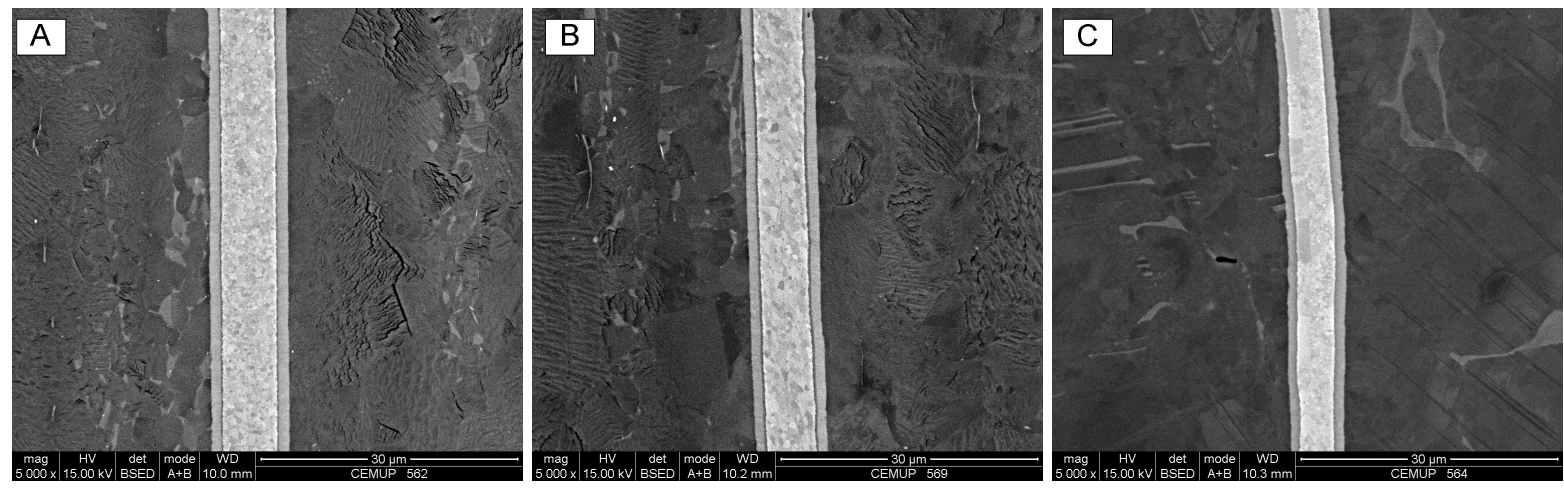

Fig. 2 - SEM images of the joints obtained at $900^{\circ} \mathrm{C}$, during 60 min with $5 \mathrm{MPa}$ pressure and multilayers with periods of: A. $30 \mathrm{~nm}$; B. $14 \mathrm{~nm}$; C. $5 \mathrm{~nm}$.
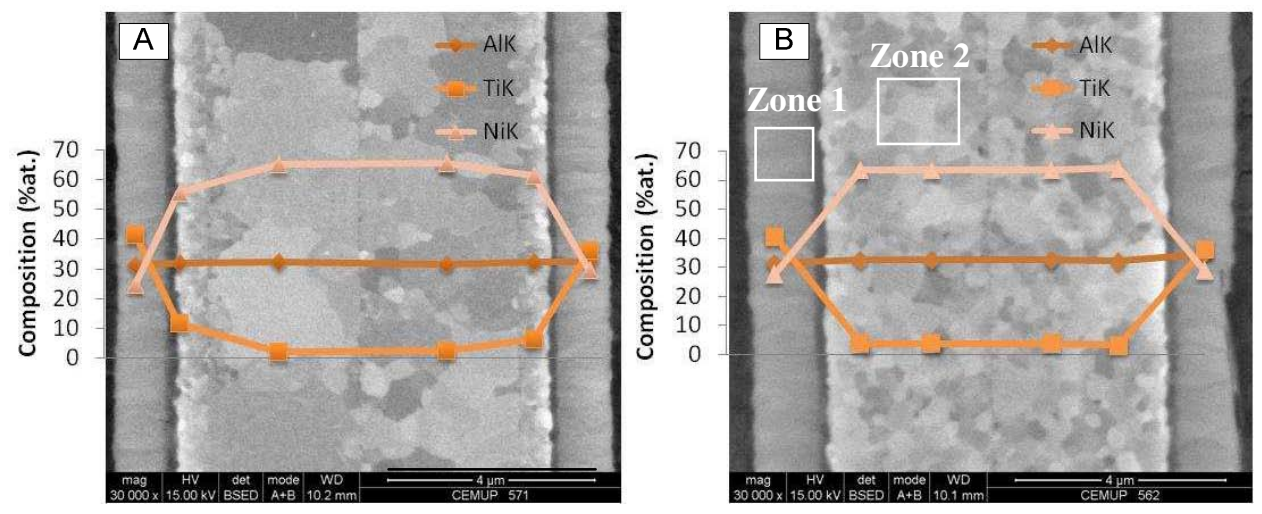

Fig. 3 - SEM images of the joint obtained at $900^{\circ} \mathrm{C}$ with $5 \mathrm{MPa}$ for samples with $14 \mathrm{~nm}$ of period multilayer: A. bonding time of $30 \mathrm{~min}$; B. bonding time of $60 \mathrm{~min}$. 